\title{
Cuaderno de Bitácora de CiberDerecho
}

FRANCISCO PÉREZ BES

Of Counsel. Coordinador del área de Derecho y Economía

Digital Gómez-Acebo\&Pombo

Bitácora de CiberDerecho (enero 2018)

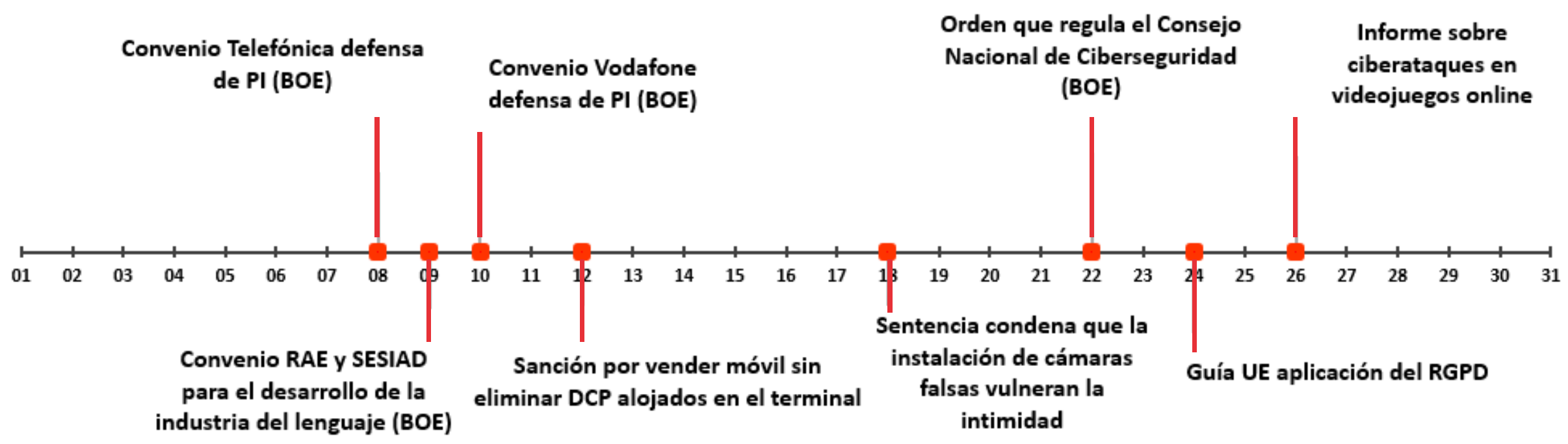




\section{Bitácora de CiberDerecho (febrero 2018)}

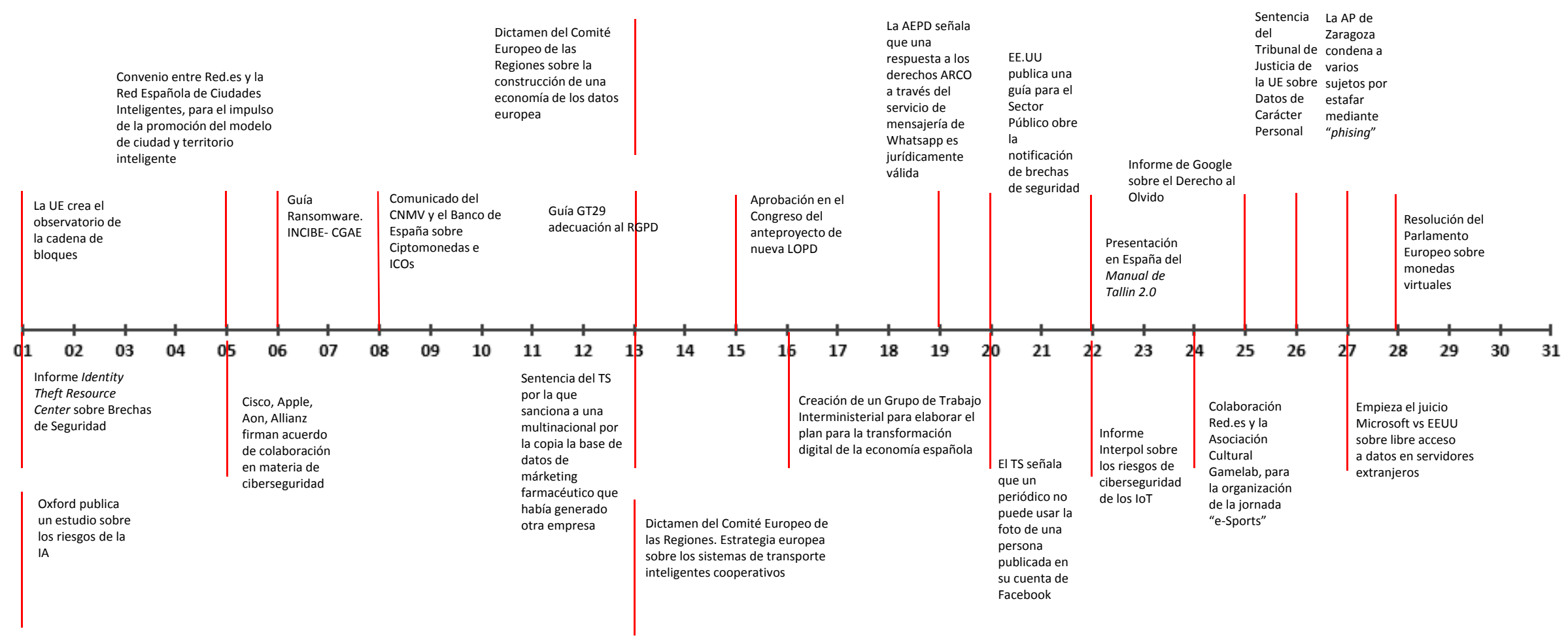




\section{Bitácora de CiberDerecho (marzo 2018)}

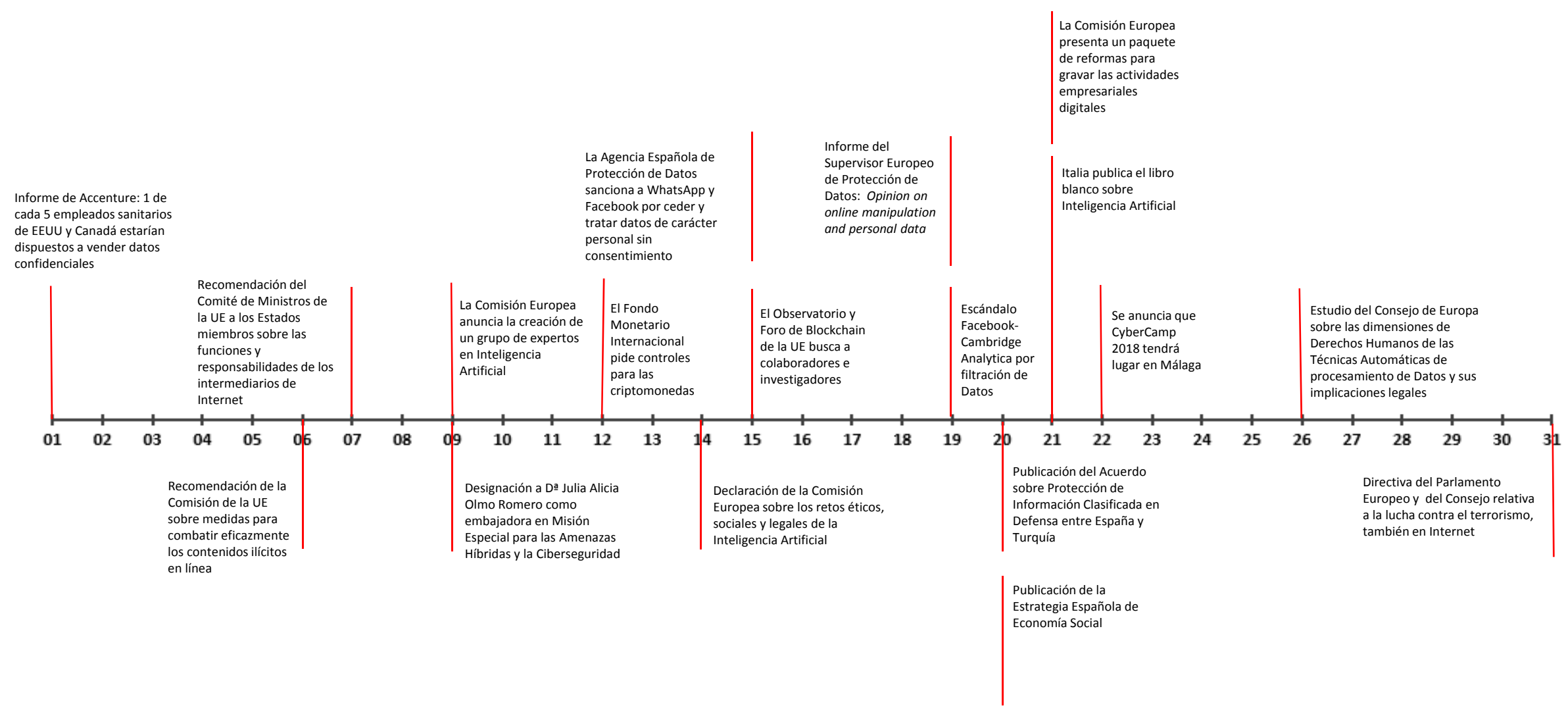




\section{Bitácora de CiberDerecho (abril 2018)}

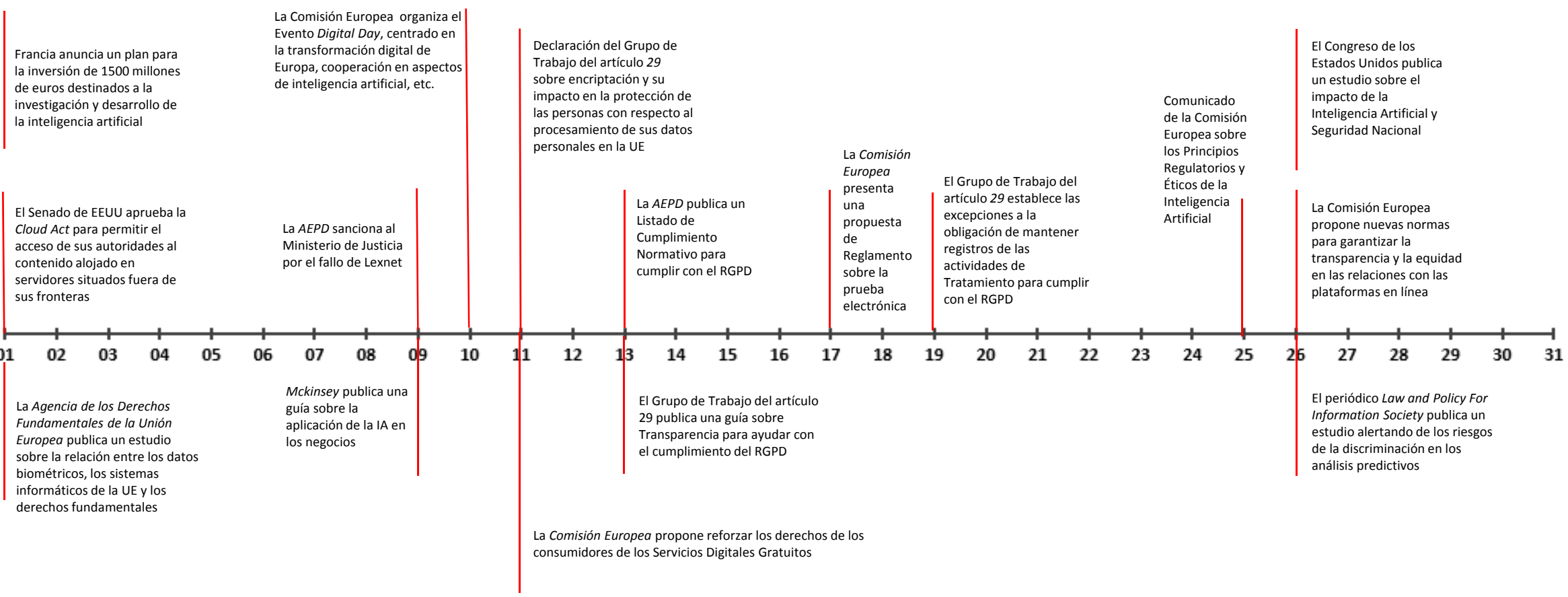




\section{Bitácora de CiberDerecho (mayo 2018)}

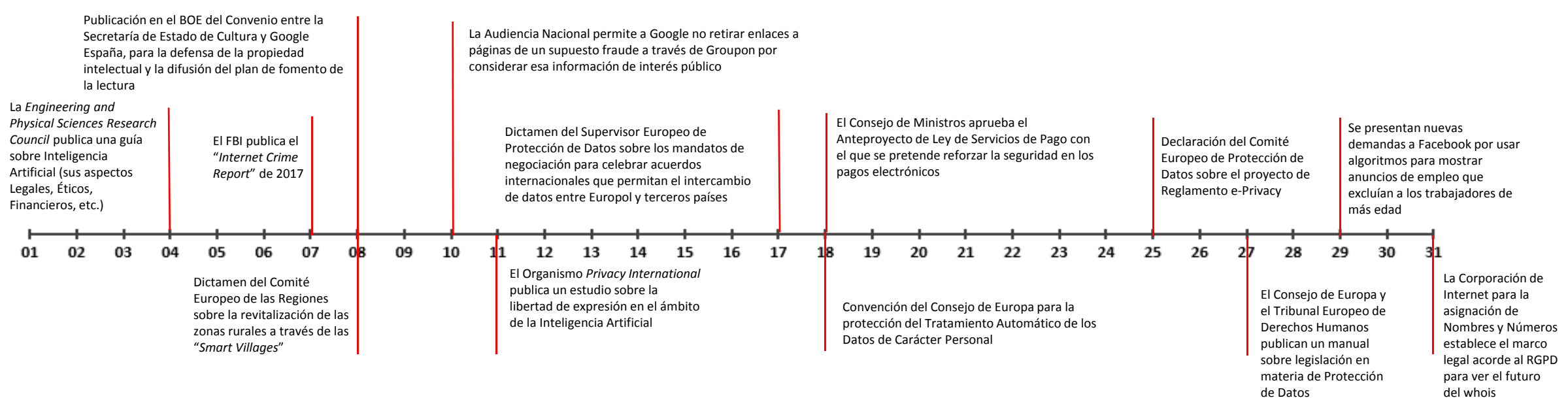




\section{Bitácora de CiberDerecho (junio 2018)}

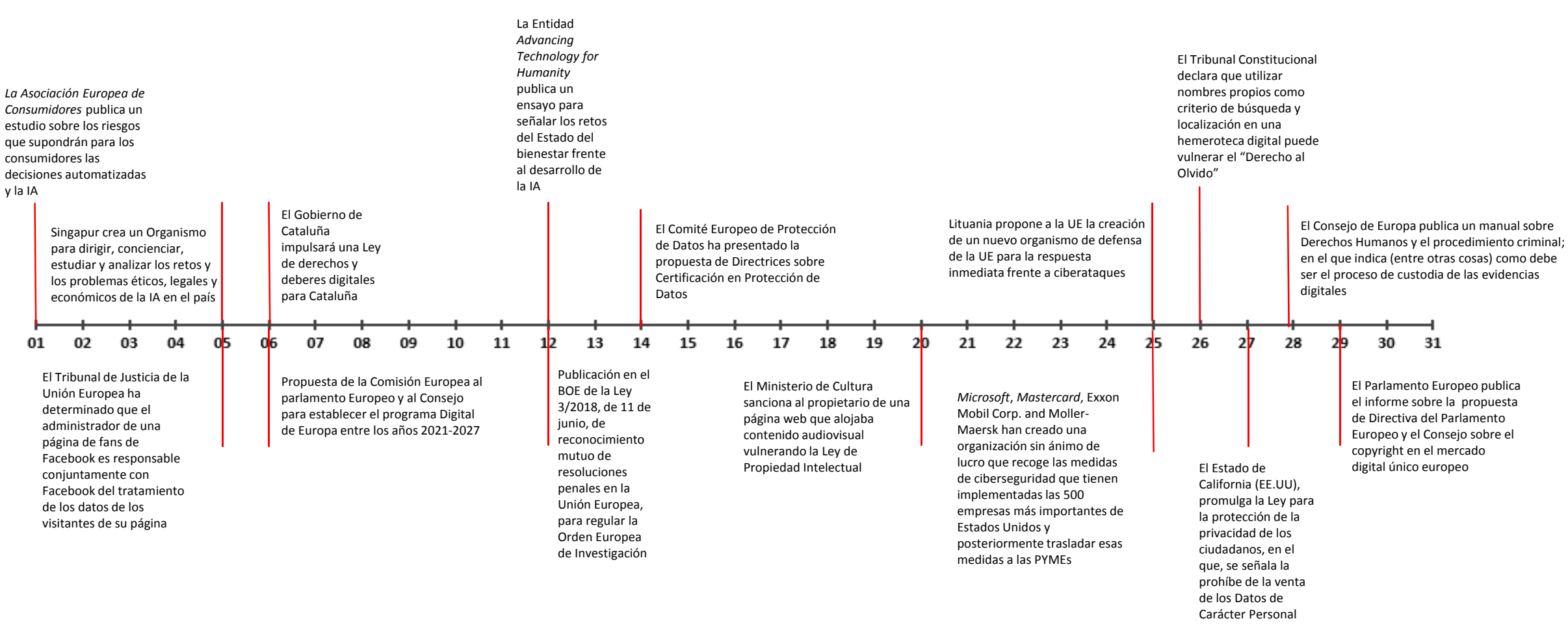




\section{Bitácora de CiberDerecho (julio 2018)}

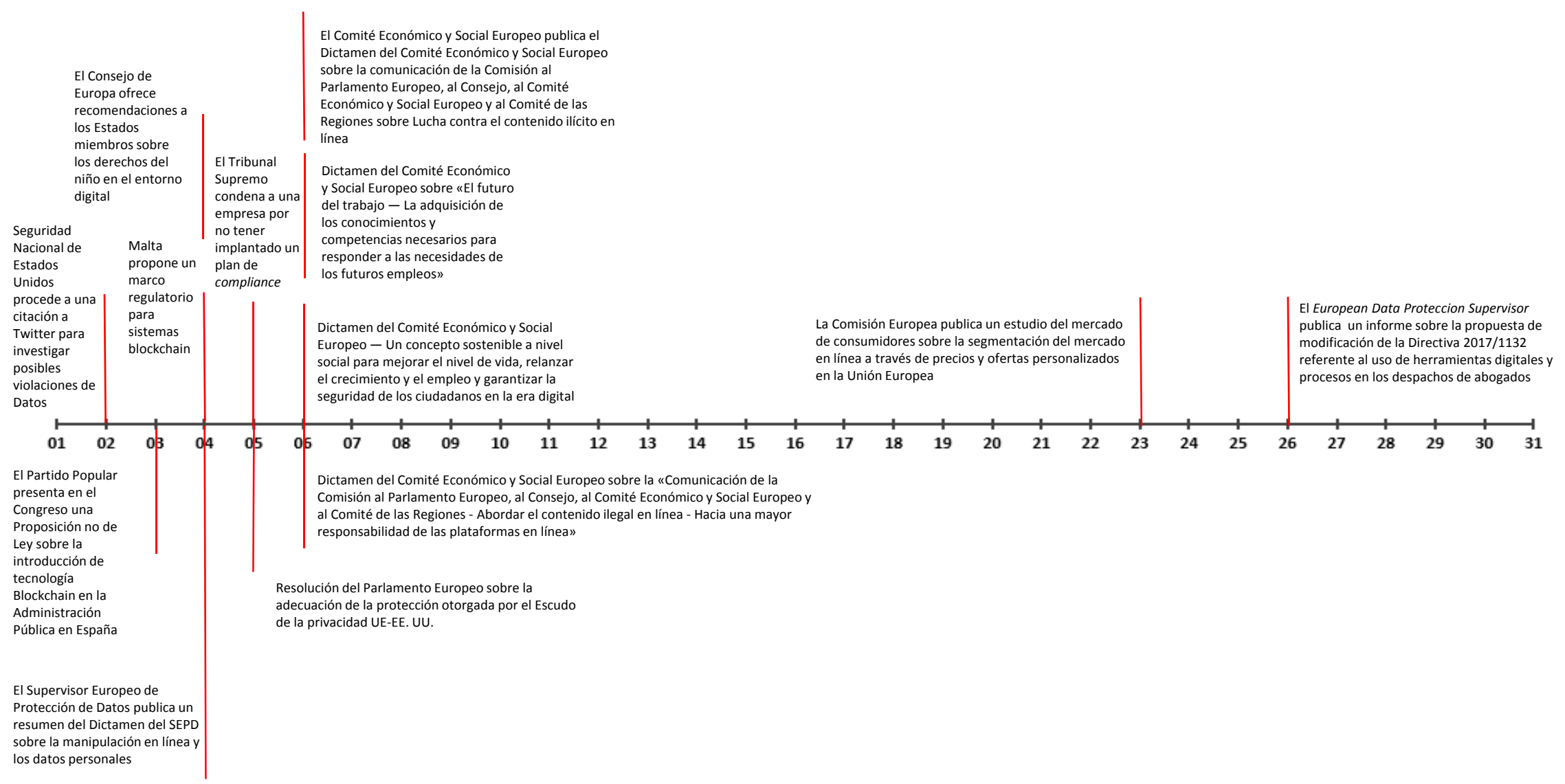




\section{Bitácora de CiberDerecho (septiembre 2018)}

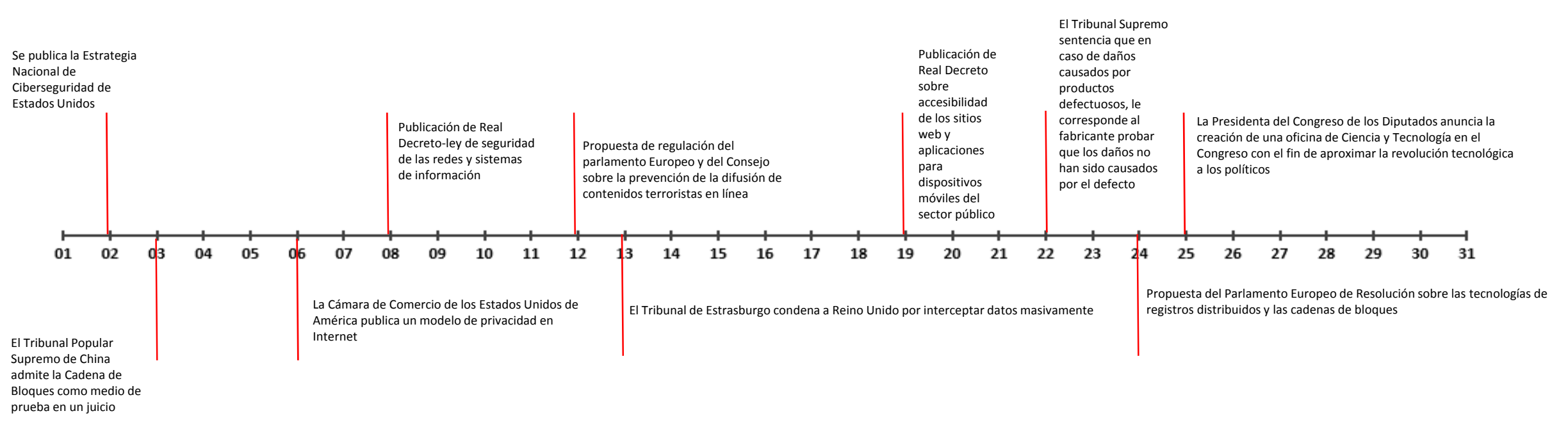




\section{Bitácora de CiberDerecho (octubre 2018)}

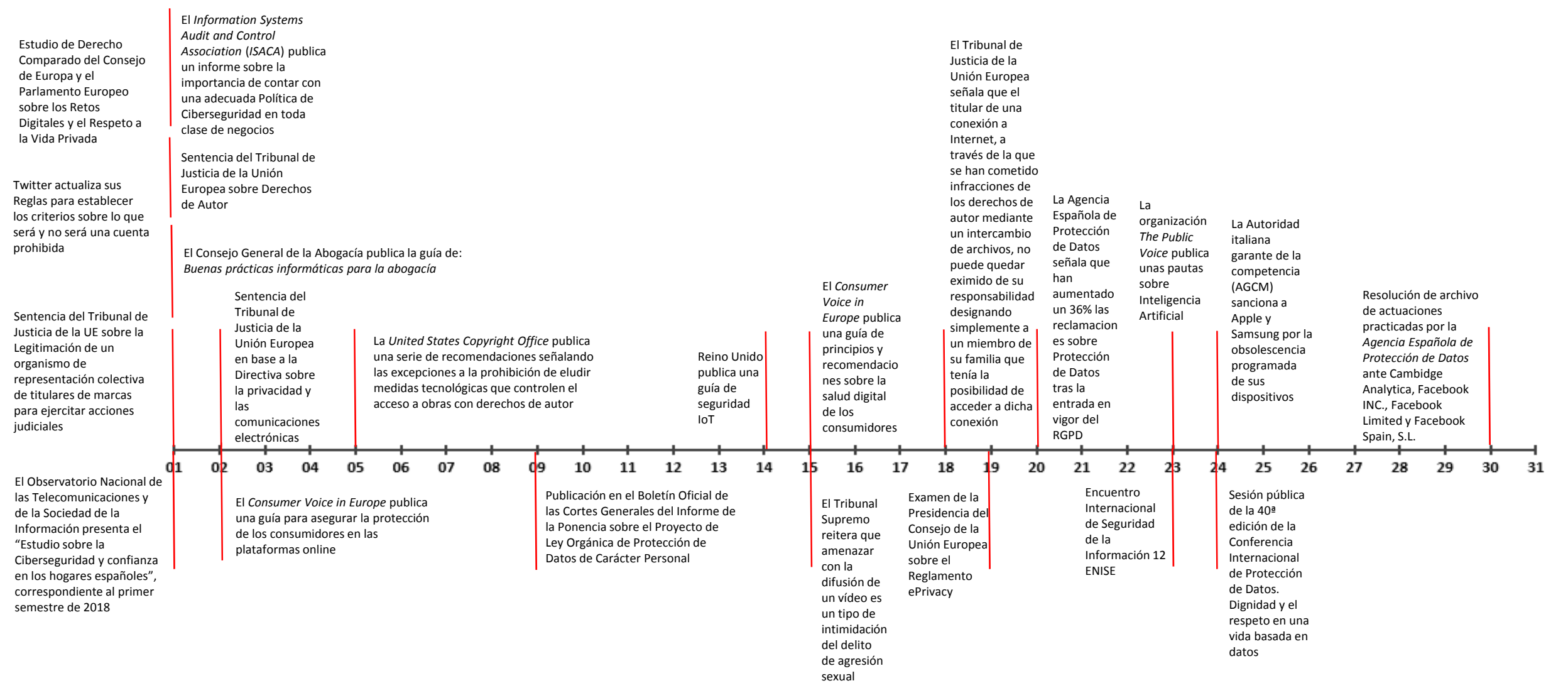




\section{Bitácora de CiberDerecho (noviembre 2018)}

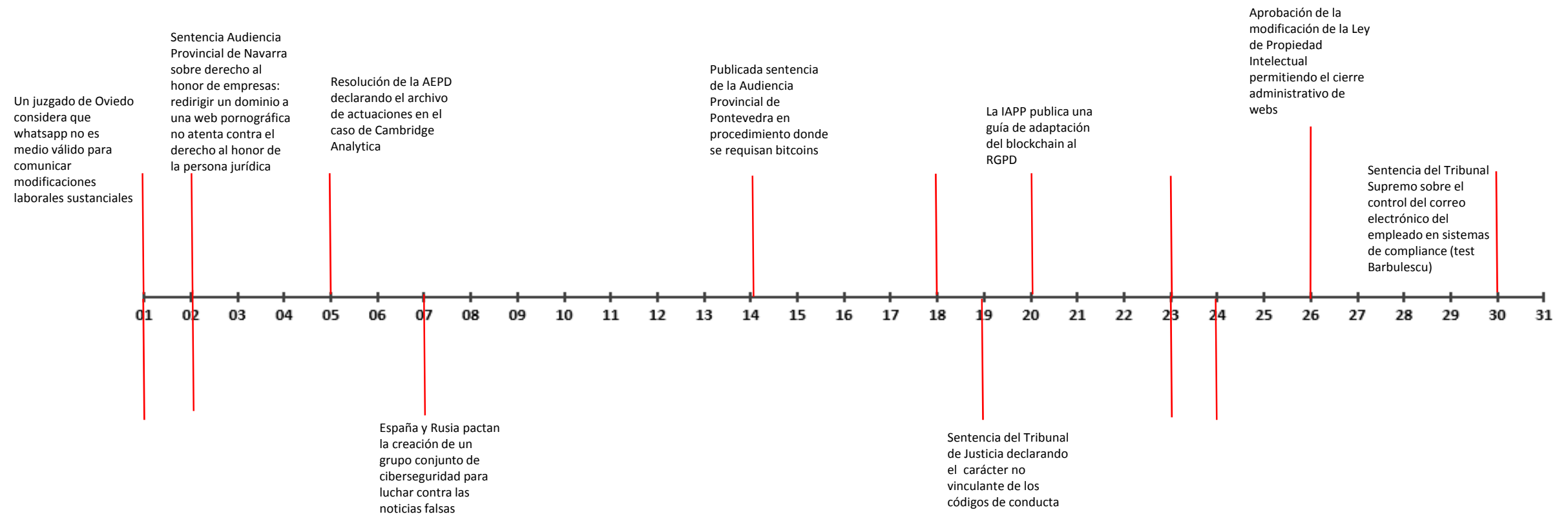




\section{Bitácora de CiberDerecho (diciembre 2018)}

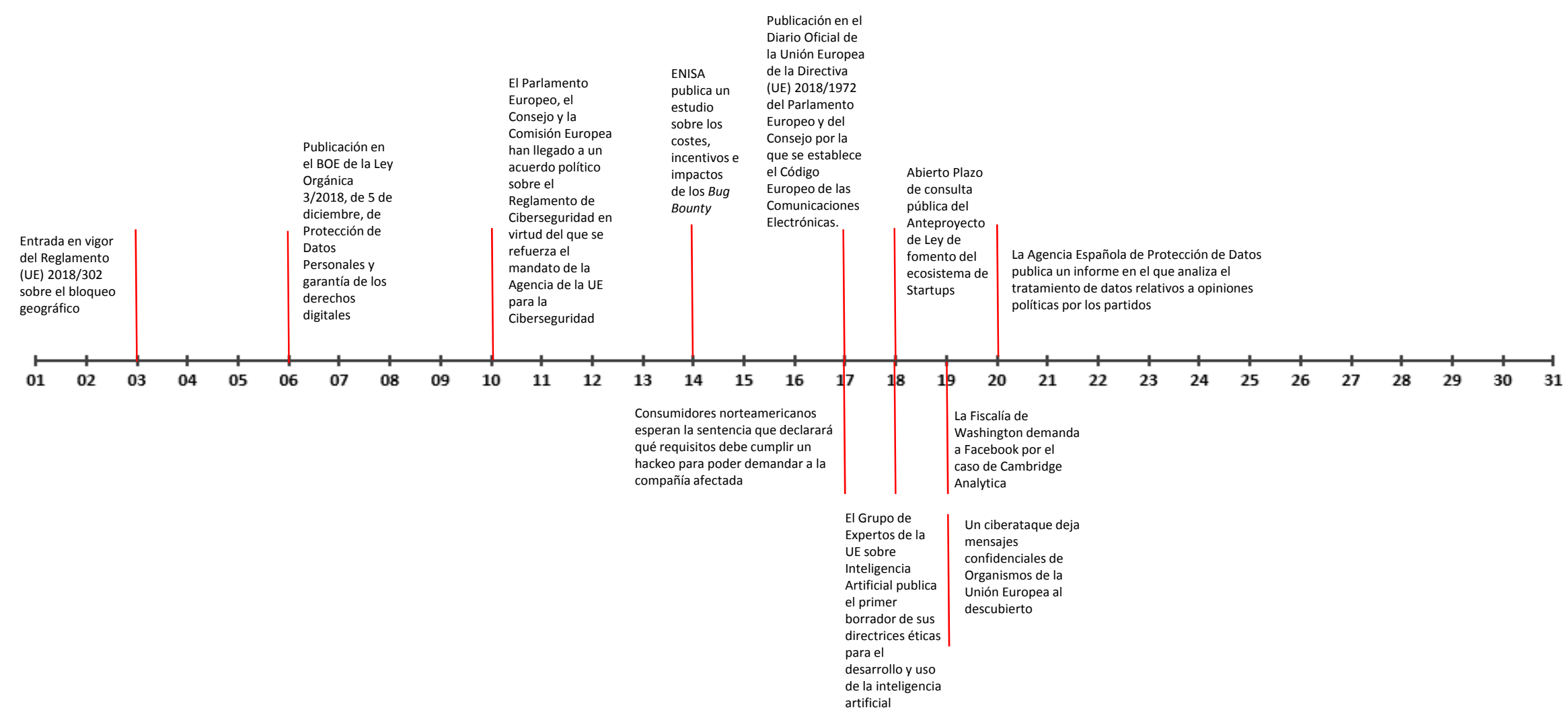

